Istanbul Finance Congress, November 1-2, 2018, Istanbul, Turkey.

\title{
AN ANALYSIS OF EXCHANGE RATE POLICIES OF ASIAN ECONOMIES
}

\author{
DOI: 10.17261/Pressacademia.2018.982 \\ PAP-IFC- V.8-2018(14)-p.61-65
}

\section{Nuray Terzi}

Marmara University, Department of Economics, Goztepe Campus, Goztepe, Istanbul, Turkey. nurayterzi@marmara.edu.tr, ORCID: 0000-0002-4141-7529

\section{To cite this document}

Terzi, N. (2018). An analysis of exchange rate policies of Asian economies. PressAcademia Procedia (PAP), V.8, p.61-65.

Permemant link to this document: http://doi.org/10.17261/Pressacademia.2018.982

Copyright: Published by PressAcademia and limited licenced re-use rights only.

\begin{abstract}
Purpose- The fact that unsustainable exchange rate policies lead to financial crises becomes the focus of debates in economics. With the global financial crisis, these debates has been revived. Therefore, this study aims to analyze the exchange rate policies of selected Asian economies.

Methodology- The exchange rate policies of Asian economies will be evaluated within a theoretical framework. In the light of IMF reports, exchange rate policies of Asian countries will be examined and relevant literature will be evaluated.

Findings- The exchange rate policies of Asian economies have constantly changed. They preferred to intervene in the market, even if they switched from fixed exchange rates to flexible rates. The effects of both economic and political factors are observed in exchange rates policies.

Conclusion- The increase in world integration of Asian economies affects exchange rate policies. Both internal factors and external factors were influential in exchange rate policies
\end{abstract}

Keywords: Exchange rate, political economy, Asian economies, financial crisis, economy policies.

JEL Codes: F30, O10, F50

\section{ÖZET}

Amaç - Sürdürülemez döviz kuru politikalarının finansal krizlere yol açması, ekonomideki tartışmaların odak noktasını oluşturmaktadır. Küresel finansal krizi, bu tartışmaları yeniden gündeme gelmiştir. Bu nedenle, çalışma seçili Asya ekonomilerinin döviz kuru politikalarını analiz etmeyi amaçlamaktadır.

Metodoloji - Asya ekonomilerinin döviz kuru politikaları teorik bir çerçevede değerlendirilecektir. IMF raporları ışığında, Asya ülkelerinin döviz kuru politikaları incelenecek ve ilgili literatür değerlendirilecektir.

Bulgular- Asya ekonomilerinin döviz kuru politikaları çok sık değişmiştir. Sabit döviz kurlarından esnek oranlara geçiş yapsalar da piyasaya müdahale etmeyi tercih etmektedirler. Döviz kuru politikalarında hem ekonomik hem de politik faktörlerin etkileri gözlenmektedir.

Sonuç- Asya ekonomilerinin dünya entegrasyonundaki artış, döviz kuru politikalarını etkilemektedir. Döviz kuru politikalarında hem iç faktörler hem de dış faktörler etkili olmaktadır.

Anahtar Kelimeler: Döviz kurları, politik ekonomi, Asya ekonomileri, finansal krizler, ekonomi politikalar JEL Codes: F30, O10, F50

\section{Giriş}

Döviz kuru rejimleri ülkelerin ekonomik büyüme, enflasyon ve üretim çeşitliliği üzerindeki etkili olmaktadır. Enflasyon, sabit kur rejimlerinin uygulandığı ülkelerde esnek rejimlere oranla daha düşük ve daha az volatil olmaktadır. Bir başka araştırmada da döviz kuru rejimleri ile büyüme arasında bir ilişki bulunmuştur. Esnek kur rejiminin uygulandığı ülkelerde daha yüksek büyüme görülmüştür. Bu ülkeler aynı zamanda uluslararası sermaye piyasalarına açık ülkeler olup, gelişmiş bir finansal piyasaya sahiptir. Daha az esnek kur rejimine sahip olan ülkelerde ise büyüme daha yavaş gerçekleşmektedir ve bu gruptaki ülkeler ise daha çok gelişen ülkelerdir. Asya ekonomilerinin döviz kuru rejimlerine yönelik tartışmalar küresel finans krizi ile artmıştır. Asya ekonomilerinin rekabetçi döviz kuru politikaları eleştirilmektedir. Bu bağlamda, çalışma ile Asya ekonomilerinin döviz kuru politikaları analiz edilmeye çalışılacaktır. Çalışma Asya ekonomilerinin bütününden ziyade birkaçına odaklanmaktadır: Endonezya, Kore, Malezya, Filipinler ve Tayland. Bu amaçla izleyen bölümde döviz kuru sistemlerinden bahsedilecek, sonrasında seçili Asya ekonomilerinin döviz kuru politikalarının yıllar içindeki değişimi verilecektir. Son olarak döviz kuru sistemlerinin seçiminde belirleyici olan dinamiklere yer verilerek değerlendirme yapılacaktır.

\section{LITERATÜR INCELEMESi}

Genel olarak döviz kuru sistemleri, sabit kurlar, ara kurlar ve enek kur sistemleri olarak sınıflandırılabilir. Sabit kurlar arasında dolarizasyon, para kurulu ve parasal birlikler sayılabilir. Hedef bölgeler, kaygan aralık, ayarlanabilir sabit kur, sürünen parite ve sürünen bantlar ara kur 
sistemleridir. Yönetimli dalgalanma ve serbest dalgalanma ise esnek kurlar arasında yer alır (IMF, 2012; Frankel, 1999). IMF'nin 189 üyeyi kapsayan döviz kuru düzenlemelerini içeren raporuna göre 2017 yılında döviz kurlarının ülkeler arasındaki dağılımı şu şekildedir: Toplam 189 ülkenin \% 42'si ara kurları tercih ederken, \% 39'u esnek kurları uygulamaktadır. Sabit kur ülkelerin \% 12'si tarafından uygulanmaktadır. Geri kalan ülkeler ise sınıflandırma dışındaki uygulamaları tercih etmişlerdir. Buradan da anlaşılacağı üzere dünya ekonomileri giderek daha esnek kurlara doğru bir geçiş yapmaktadır. Katı sabit kurlar terk edilmekte, ülkelerin para politikalarına daha uygun olan esnek kurlar tercih edilmektedir. Sabit kur ve esnek kurların avantaj ve dezavantajları aşağıdaki tablodaki gibi özetlenebilir (Tablo 1).

Tablo 1: Sabit ve Esnek Kurların Avantaj ve Dezavantajları

\begin{tabular}{|c|c|}
\hline SABIT KURLAR & ESNEK KURLAR \\
\hline Avantajları & Avantajları \\
\hline$\checkmark \quad$ MB'nın enflasyon ile mücadelesinde esneklik & $\checkmark \quad$ Bağımsız para politikasının uygulanabilmesi \\
$\quad$ sağlaması & $\checkmark \quad$ Ticari şoklara otomatik uyum sağlaması \\
$\checkmark \quad$ Belirsizliği ortadan kaldırması & $\checkmark \quad$ Bürokrasiyi azaltması \\
$\checkmark \quad$ Yatırımcıya güven vermesi & $\checkmark \quad$ Dış dengenin kendiliğinden sağlanması \\
$\checkmark \quad$ Rekabetçi devalüasyonları önlemesi & $\checkmark \quad$ Aşırı volatilite/aşırı dalgalanmanın önüne geçmesi \\
$\checkmark \quad$ İşlem maliyetlerini düşürmesi & \\
$\checkmark \quad$ Dalgalanma korkusunu azaltması & \\
\hline Dezavantajları & Dezavantajları \\
\hline$>\quad$ Aşırı değerlenme & $>\quad$ Geleceğe ilişkin belirsizlikler taşıması \\
$>\quad$ Bürokrasi & $>\quad$ Spekülatif ataklar \\
& $>\quad$ Sürekli artışın enflasyonist etkisi \\
\hline
\end{tabular}

Sabit döviz kurunun seçilme nedenleri arasında merkez bankasının enflasyon ile mücadelesinde daha fazla kredibilite sağlaması yatar. Ücret ve fiyat belirleyicileri, gelecekteki enflasyonu düşük olarak algılar ya da yüksek enflasyonun merkez bankası tarafından kurlar yolu ile engelleneceğini düşünülür. Böylece ücret ve fiyat kararlarını da düşük olarak tespit edebilirler. Sabit döviz kurunun istenmesinin bir diğer nedeni esnek kur sisteminin yarattığı belirsizliktir. Bu tür bir risk uluslararası ticaret ve yatırımların cesaretini kırar. Sabit kur, uluslararası yatırımcıya güven verir, döviz kuru riskini azaltarak uluslararası ticaret ve yatırımları teşvik eder. Sabit döviz kurunun sağladığı diğer bir avantajı da rekabetçi devalüasyonları ya da rekabetçi revalüasyonların önlemesidir (Frankel, 2004).

Esnek döviz kuru sistemi de ülkenin bağımsız para politikası uygulamasının önünü açar. Sabit kurun aksine, herhangi bir şekilde talepte düşme ve böylece resesyona gitme sürecinde hükümet rahatlıkla politika uygulayabilir. Esnek kurun diğer bir avantajı, ticari şoklara karşı otomatik uyum mekanizmasıdır. Para, ülkenin ihraç piyasasındaki gelişmelere olumlu cevap verir, paranın değer düşüşü ile ticaret hadleri değişir. Böylece gerekli reel değer düşüşü de sağlanmış olur. Diğer bir avantajı da spekülatif balonları önlemesidir. Sabit kurda karşılaşılan aşırı değerlenme ve aşırı volatilite, esnek kur sisteminde azalır (Frankel, 2004). Esnek kur sistemi, piyasa koşullarını azami düzeyde işleterek ekonomik etkinliği ve disiplini sağlar. Ülkenin parası değer kazanıyorsa yatırımcıların güveni sağlanmış demektir, değer kaybediyorsa yatırımcıların ekonomiye güveni azalmıştır. Esnek kurlar, devletin kur düzeyini veya aralığını değiştirmek zorunda kalacağına ilişkin spekülasyon zeminini de ortadan kaldırır. Sabit kura kıyasla esnek kur sistemi finansal istikrarı daha iyi sağlar. Çünkü esnek kur rejiminde devletin belirlenen bir kuru koruma kararlılığını spekülatörlerin sınamasına gerek yoktur. Kur sistemlerinin kendine özgü nitelikleri, ülkeleri kendi politikalarına uyum sağlayabilecek döviz kurlarını seçmeye yöneltmiştir. Asya ekonomileri de aşağıda görüleceği üzere zaman içinde esnek kur sistemini tercih etmişlerdir.

\section{SEÇiLI ASYA EKONOMILERININ DÖVIZ KURU POLITIKALARI}

Asya finansal krizi öncesinde belli başlı Asya ekonomilerinin döviz kuru politikaları değişkenlik gösterir. Endonezya ve Kore 1980'li yıllardan bu yana yönetimli dalgalanmayı tercih etmişlerdir. Malezya'nın döviz kuru politikası çok sık değişir. 1990'a kadar sınırlı esnekli bir sistemi kullanır ve daha sonra iki sene sabit kur uygular. Hemen sonrasında yönetimli dalgalanmaya geçer, sonra tekrar ayarlanabilir sabit kurlara döner. Filipinler ise döviz kuru rejiminde bağımsız dalgalanmayı seçer. Tayland'da ise finansal krize kadar sabit kur hakim olmuştur(Tablo 2).

Tablo 2: Seçili Asya Ülkelerinde Döviz Kuru Rejimleri, 1970 - 2000

\begin{tabular}{|l|l|l|}
\hline Endonezya & Kasım 1978- Haziran 1997 & Yönetimli Dalgalanma \\
& Temmuz 1997- Aralık 2000 & Bağımsı Dalgalanma \\
\hline Kore & Mart 1980 -Ekim 1997 & Yönetimli Dalgalanma \\
& Kasım 1997- Aralık 2000 & Sinırlı Esneklik Dalgalanma \\
\hline Malezya & Ocak 1986- Şubat 1990 & Sabit \\
& Mart 1990 - Kasım 1992 & Yönetimli Dalgalanma \\
& Aralık 1992 -Eylül 1998 & Ayarlanabilir Sabit Kur \\
\hline Filipinler & Eylül 1998-Aralık 2000 & Bağımsız Dalgalanma \\
\hline Tayland & Ocak 1988- Aralık 2000 & Sabit Kur \\
& Ocak 1970 - Haziran 1997 & Bağımsız Dalgalanma \\
\hline
\end{tabular}

Kaynak: Hernandez, L ve Peter. J. Montiel, “Post-Crisis Exchange Rate Policy in Five Asian Contries, Filling in the Hollow Middle ? IMF, 2001. 
Calvo ve Reinhart (2000)'a göre Asya ekonomilerinin pek çoğu resmi olarak esnek bir kur rejimine sahip olsa da dalgalanma korkusu nedeniyle döviz piyasalarına müdahalede bulunabiliyorlardı. Asya finansal krizi bu ekonomileri oldukça kötü etkilemiştir. Bu ekonomilerin, yeterli döviz rezervleri olmadığından Tayland, Endonezya ve Malezya'nın çok kısa bir süre içinde paralarının değeri düşmüş ve yarısından fazlasını kaybetmişlerdir. Malezya hükümeti hemen sermaye kontrolü uygulamaya başlamıştır ve Malezya ringgit'ini dolara sabitlemiştir. Endonezya, Kore ve Tayland kriz sonrası esnek döviz kuru rejimine geçerler (McKinnon 2001). Ancak bu ekonomilerin kriz sonrasında da değerlenme korkusu yaşadıkları açık bir şekilde gözlenmiştir. Asimetrik döviz kuru müdahalelerinden de bu oldukça net anlaşılmaktadır. Ayrıca Asya ekonomileri, paralarının değerinin yükselmesini arzu etmemişlerdir. Bu nedenle de 2000'li yıllarda Asya ekonomilerinin çoğu yönetimli dalgalı kura geçmekle birlikte müdahalede bulunmaya devam etmişlerdir. Bu da Asya ekonomilerinin gerçekte ve uygulamadaki rejimlerinin farklı olmasına yol açmıştır(Tablo 3).

Tablo 3: Seçili Asya Ülkelerinde Döviz Kuru Rejimleri, 2000- 2013

\begin{tabular}{|c|c|c|}
\hline Endonezya & $\begin{array}{l}\text { Aralık } 2000 \text { - Aralık } 2001 \\
\text { Aralık } 2002 \text { - Nisan } 2008 \\
\text { Nisan } 2009 \text { - Nisan } 2012 \\
\text { Nisan } 2013\end{array}$ & $\begin{array}{l}\text { Bağımsız Dalgalanma } \\
\text { Yönetimli Dalgalanma } \\
\text { Dalgalı Kur } \\
\text { Sürünen Parite Benzeri Düzenleme }\end{array}$ \\
\hline Kore & $\begin{array}{l}\text { Aralık } 2000 \text { - Nisan } 2008 \\
\text { Nisan } 2009 \\
\text { Nisan } 2010 \text { - Nisan } 2013\end{array}$ & $\begin{array}{l}\text { Bağımsız Dalgalanma } \\
\text { Serbest Dalgalanma } \\
\text { Dalgalı Kur }\end{array}$ \\
\hline Malezya & $\begin{array}{l}\text { Aralık 2000- Aralık } 2004 \\
\text { Nisan } 2004 \text { - Nisan } 2008 \\
\text { Nisan } 2009 \text { - Nisan } 2013 \\
\end{array}$ & $\begin{array}{l}\text { Konvansiyel Sabit kur uyg. (ABD Doları) } \\
\text { Yönetimli Dalgalanma } \\
\text { Diğer Yönetimli Düzenlemeler }\end{array}$ \\
\hline Filipinler & $\begin{array}{l}\text { Aralık } 2000 \text { - Nisan } 2008 \\
\text { Nisan } 2009 \text { - Nisan } 2013\end{array}$ & $\begin{array}{l}\text { Bağımsız Dalgalanma } \\
\text { Dalgalı Kur }\end{array}$ \\
\hline Tayland & $\begin{array}{l}\text { Aralık } 2000 \text { - Aralık } 2001 \\
\text { Aralık } 2002 \text { - Nisan } 2008 \\
\text { Nisan } 2009 \text { - Nisan } 2013\end{array}$ & $\begin{array}{l}\text { Bağımsız Dalgalanma } \\
\text { Yönetimli Dalgalanma } \\
\text { Dalgalı Kur }\end{array}$ \\
\hline
\end{tabular}

Kaynak: IMF, Annual Report on Exchange Arrangements and Exchange Restrictions (2001-2013); and IMF, International Financial Statistics (2000); Kawai ve Pontines, 2014.

Doğu Asya ekonomileri yakın zamanlara kadar paralarının değerinin yönetiminde doları hedef olarak almışlardır. Yani Asya krizi sonrasında doların bölgedeki hakimiyeti devam etmiştir (Kawai ve Pontines, 2014). Kimileri doların bölgedeki hakimiyetini ifade etmek üzere Doğu Asya Dolar Bölgesi ya da Doğu Asya Dolar Standardı ifadelerini kullanmıştır. Kimileri de bu durumu Bretton Woods'un 1973'te çöküşü ile birlikte, ABD’nin merkezinde II. Bretton Woods uluslararası para sisteminin yeniden doğuşu olarak nitelemişlerdir. Pek çok ülke kendi parasının aşırı bir şekilde değerlenmesinden kaçınmaktadır. Bu yüzden Asya ekonomilerinin bazıları "Parasal Merkantalizm” davranışı ile yani aktif müdahale ile paralarının değerini düşük tuttukları için eleştirilmiştir (Aizenman ve Lee, 2008). Fakat son birkaç yılda bu durum değişmektedir. Yeni araştırmalar Doğu Asya'nın dolar blokundan renminbi blokuna doğru geçiş yaptığını gösteriyor. Para sepetleri içinde renminbinin ağırlığı giderek artıyor (Kawai ve Pontines, 2014). 2005 ve 2009 yılları arasında Çin dolar karşısında renminbi'nin kontrollü bir şekilde değerlendirilmesi politikasını uyguladığında, diğer ekonomiler bir seçim ile karşı karşıya kalmışlardır. Ya paralarını renminbi karşısında değerlenmesine izin verecek ya da dolara bağlı yumuşak rejimi uygulamaya devam edecekti. Bölgedeki gelişen ekonomilerin çoğu renminbi karşısında değerlenme stratejisini seçti. 2010 yılından bu yana Çin, diğer ekonomiler renminbi'ye karşı değerlenmeyi seçseler bile renminbi'nin değerlenmesi karşısında sıkı bir kontrol uyguladı. Bu paralar ile renminbi arasında ortak hareket giderek daha sıkı olmaya başladı. Şimdi renminbi, bölgedeki diğer ekonomilerin referans parası olmak için doları ya da euroyu gölgede bırakmaktadır (Wang, 2014, Caporale ve diğerleri, 2016).

\section{BULGULAR VE TARTIŞMA}

2017 yılı itibariyle belirtilen beş Asya ekonomisi (Kore, Endonezya, Malezya, Filipinler, Tayland) dalgalı kur sistemini uygulamaktadır (IMF, 2017). Asya ekonomilerinin dünya ekonomisi ile entegrasyonu arttıkça esnek kurun avantajını almışlar, dalgalı kurda kalmayı tercih etmişlerdir. Döviz kuru politikalarının seçimi diğer ekonomi politikaları gibi salt ekonomik mantık ile açıklanamaz. Özellikle 1950’lerden 1970'lere Doğu Asya'nın ekonomik kalkınmasının politik ekonomisi üzerine odaklanan literatür ulusal politik kurumların ve uluslararası politik çevrenin merkezi rolünü vurgulamıştır (Wang, 2014). Döviz kurlarının seçiminde para politikalarının etkisi önemlidir. Özellikle enflasyonun yükselmesinden çekinen ülkeler döviz kurlarının dalgalanmasından yana değildir. Hele ki bu ülkeler para politikası olarak enflasyon hedeflemesini seçmişler ise döviz kurlarının istikrarlı kalmasını istemişlerdir. Benzer biçimde bu ülkeler uluslararası rekabet güçlerini kaybetmek istememişlerdir. Çünkü paralarının değerlenmesi rekabet kaybına yol açacak bu da ihracatlarını negatif olarak etkileyebilecekti (Tiwari, 2003). Ayrıca Asya ekonomileri uluslararası piyasalara girişte diğer ekonomiler ile aynı koşullara sahip değildi. Döviz kurlarındaki yüksek volatilite kredi derecelendirme kuruluşlarının düşük notlandırmasına neden olmakta ve yabancı yatırımcıların girmesini engellemekteydi (Calvo ve Reinhart, 2000). Bu nedenle de yarı esnek uygulamalara geçişi desteklemişlerdir.

Döviz kurlarının yönetiminde uluslararası rekabete önem vermişlerdir. Son yıllarda bölge ekonomilerinin döviz kurları daha stabil kalmıştır. Bu durum bölge ekonomilerinin biraraya gelerek anlaşmaya vardıkları bir sonuç değildi. Asya ekonomileri cari fazlayı sürdürülebilir kılmak istemişlerdir. Bu nedenle döviz kurlarını belli seviyede tutarak uluslararası rekabetçi güçlerini korumuşlar ve cari fazlaya ulaşmışlardır (Hamilton-Hart, 2011). Ayrıca iş dünyasına güven vermek gerekliydi. İstikrarlı bir kur, iş dünyasını pozitif etkilemekte bu da piyasa üzerinde olumlu etki yaratmakta idi. Örneğin Tayland ekonomisi, daha geniş bir aralıklar ile dalgalanan bir kuru yönetemeyecek kadar küçük bir ülke olduklarını düşünmekteydi ve bu nedenle sabit kurda kalarak iş dünyasına güven vermeye çalışmışlardı (Krugman, 2010). Doğu Asya döviz 
kurlarına ilişkin son gelişmelerden biri renminbi blokunun oluşumudur. Çin hızla gelişen bir Pazar olarak bölgesel ticaret ve yatırımların merkezi olmaktadır. Bu da Çin'e kendi komşu ülkeleri üzerinde parasal tercihini empoze etme gücü vermektedir. Aynı zamanda diğer ekonomiler için Renminbi'yi izleme konusunda bir teşvik yaratmaktadır. Kısacası renminbi bloku, Çin'in yapısal gücünün bir sonucudur. Çin giderek artan bir biçimde bölgede parasal işbirliğinin öncülüğünü üstlenmektedir. Renminbi tahvilleri Hong Kong dışındaki finans merkezlerine taşınması, Londra ve Singapur piyasalarında işlem görmeye başlaması Çin'in yayılmacı etkilerinin sonucudur (Kroeber, 2017).

Devlet politikaları ekonomi politikaları üzerinde önemli rol oynasa da bazı araştırmalar çıkar gruplarının rolüne odaklanır. Bazı ülkelerdeki demokratikleşme süreci örneğin Kore ve Tayland'da iş dünyasına seçim sonuçlarını etkileme kabiliyeti verdi. Endonezya ise döviz kurlarını dengeli kullanan tek istisna ülke idi. İhracatçılardan ziyade döviz kurlarını tüm gruplar lehine kullanmayı seçmiştir. Bu Endonezya'nın geldiği demokratikleşme süreci ve hükümetin toplumu bir bütün olarak yönetme isteğinden kaynaklanmaktaydı (Hamilton-Hart, 2013). Sonuçta iş dünyası ile hükümet arasındaki politik bağlar azımsanmayacak kadar kurların seçiminde etkili olmuştu. Ayrıca, ampirik araştırmalar otoriter rejimlerin demokratik rejimlere göre daha fazla sabit kur rejiminden yana olduğunu göstermektedir. Bunun sebebi otoriter rejimlerin döviz kurlarını sabit tutarak bir güven vermeye çalışma intiyacı içinde olmalarından kaynaklanmaktadır. Demokratik rejimler ise merkez bankasının bağımsızlığı ve şeffaf politikalardan yanadır Ayrıca seçim döngüsü döviz kurunun ayarlama zamanını da etkiliyor. Politikacılar seçim öncesi döviz kurunu yüksek tutma çabası içindeler ve seçim sonuna kadar da devalüasyondan kaçınıyorlar (Klein ve Marrion, 1997).

ABD’nin politikası döviz kurları üzerinde etkili olmuştur. Soğuk savaşta, Amerika'nın politik ve stratejik önceliği komünist rejimlerin etkisini azaltmak idi. Bu açıdan ABD, Asya ekonomilerine kendilerini geliştirmeleri konusunda yardımcı olmuştur. Japonya'dan diğer yeni sanayileşen Asya ekonomilerine kadar pek çok ülkeye ihracatlarını büyütmeleri konusunda desteklemiş ve bu da bu ülkelerin daha düşük kurlarla hareketlerini mümkün kılmıştır. Bunun yanında uluslararası politikadaki büyük değişimler de Doğu Asya döviz kuru rejimleri üzerinde etkili olmuştur. Soğuk savaş sonu ve iki kutuplu uluslararası güç sisteminden tek kutuplu güç sistemine geçiş ekonomik çatışmaları artıır. Özellikle batı ülkeleri arasında para savaşları başlar. Güvenlik konularındaki endişe ve korkuların azalması ile ABD ve müttefikleri Doğu Asya da parasal konular üzerinde daha az zorlayıcı olmaya başlarlar. ABD ve IMF, Kore ve diğerlerinden Asya finansal krizi sonrasında taviz isteklerinde katı uygulamalarından vazgeçerler (Cumings, 1999). 1990'ların sonundaki finansal kriz Doğu Asya ekonomileri için bir diğer dönüm noktası idi. Kriz sonrasında IMF ciddi borç yükü olan ülkelere reform ve ekonomik kalkınmaları için kurtarma paketleri önermiştir. IMF'nin baskı ve tavsiyeleri pek çok ülkeyi piyasa odaklı döviz kurlarını içeren ekonomik serbestleşmeye doğru itmiştir. IMF den yardım alan ülkeler - Kore, Tayland, Filipinler- Endonezya- dalgalı döviz kurlarına doğru bir geçiş yapmıştır.

\section{SONUC}

Asya ekonomilerinin döviz kuru politikaları zaman içinde değişim göstermektedir. Zaman içinde daha esnek kurlara geçiş yapmışlardır. Döviz kuru politikalarında hem ekonomik hem de politik faktörlerin etkileri gözlenmektedir. Asya ekonomilerinin dünya entegrasyonundaki artış, döviz kuru politikalarını etkilemektedir. Ulusal ve uluslararası faktörler, döviz kuru politikalarında etkili olmuştur. Ulusal faktörlerde ekonomi politikalarının, kurumların ve rejimlerin etkisi görülürken, uluslararası faktörler arasında ABD’nin politikası, uluslararası kurumlar ve finansal krizler yer almaktadır. Finansal krizler, Asya ekonomilerini finansal dalgalanmalara ve piyasadaki istikrarsızlıklara karşı daha temkinli davranmaya itmiştir. Döviz tercihlerinde daha esnek yaklaşımlar benimsemelerini sağlamıştır.

\section{KAYNAKÇA}

Aizenman, J ve J. Lee, (2008). Financial Versus Monetary Mercantilism, Long Run View of Large International Reserves Hoarding" World Economy 31 (5), 593-611.

Bénassy-Quéré, Agnès ve Amina Lahrèche-Révil, (2003). “Trade Linkages and Exchange Rates in Asia: The Role of China, CEPII, No. 200321,Aralık.

Calvo, Guillermo ve Reinhart, Carmen (2000): Fixing For Your Life, NBER Working Paper Series, Working Paper 8006, November.

Caporale, G.M, Luis A. Gill Alana ve Kefei You (2016) "Exchange Rate Linkages Between Asean Curencies, The US Dollar and The Chines Renminbi" Bank of Finland Research, Discussion Paper, 20.

Cumings, B. (1999) The Asian Crisis, Democracy and the End of Late Development" In T.J. Pempel (ed) The Politics of Asian Economic Crisis, Ithaca NY: Cornell University Press 17-44.

IMF (2000) 1960-2000. Annual Reports on Exchange Arrangements and Exchange Restrictions. Washington, D.C.

IMF (2012). Financial Operations and Transactions, Appendix II.

IMF (2017). Annual Report on Exchange Arrangements and Exchange Restrictions, October.

Frankel, Jeffrey A. (1999). "No Single Currency is Right for All Countries or at all Times," Princeton Essays in International Finance 215. International Finance Section. Department of Economics. Princeton University. Princeton NJ.

Frankel,Jeffrey A. (2004) “Experience and Lessons from Exchange Rate Regimes in Emerging Economies", Monetary and Financial Integration, Vol. 2, 91-138, Palgrave Macmillan Press, New York.

Hamilton-Hart, Natasha, (2011). Distribution Domestic Policies and Monetary Cooperation in East Asia, ADBI, Working Paper Series, No.332

Kawai, Masahiro ve Victor Pontines,(2014). The Renminbi and Excahnge Rate Regimes in Asia, ADBI Working Paper Series, N0.484, May. Asian Development Bank.

Kroeber, Arthur R. (2017). Çin Ekonomisi, Buzdağı Yayınevi, Ankara. 
Krugman, Paul (2010). Bunalım Ekonomisinin Geri Dönüşü ve Küresel Kriz, 6. Basım, Literatür Yayınları, İstanbul.

McKinnon, R. (2001) After the Crisis The East Asian Dollar Standard Resurrected: An Interpretation oh High Frequency Exchange Rate Pegging, HKIMR Working Paper No. 04/2001

Tiwari, Rajnish, (2003). Post-Crisis Excahnge Rate Regimes in South East Asia: An Emprical Survey of De Facto Policies, Seminar Paper, University of Hamburg, online available: http://www.rrz.uni-hamburg.de/RRZ/R.Tiwari/papers/exchange-rate.pdf

Wang, Hongying (2014). "The Political Economy of Exchange Rates in East Asia", Handbook of the International Political Economy of Monetary Relations Edited by Thomas Oatley and W. Kindred Wincoff, Edward Elgar Publishing, UK. 2014. 